\title{
Culturally Relevant Pedagogy—A Diffusion Model for District-Wide Change to Address Systemic Racism
}

Wendy Mackey

\author{
St. Francis Xavier University
}

Author Note

Correspondence regarding this article should be directed to Wendy Mackey, email: wmackey@stfx.ca

\begin{abstract}
Culturally relevant pedagogy (CRP) has been implemented in classrooms and schools across Canada and the United States to address the inequity that has caused an academic achievement gap between Black and Indigenous students and those students who self-identify as White. The purpose of this paper, which draws upon a larger instrumental case study that investigated CRP as a district-wide change, is to demonstrate an effective model for sustainable, deep-level educational change to address systemic racism through CRP. The primary research question from the larger study was: How do people with different roles throughout the hierarchy of the school district make sense of CRP? In this paper, I highlight two of the key findings from the larger study. First, in order for CRP as a district-wide reform mandate to be implemented effectively, the steps of the reform must be diffused throughout the district rather than decreed from the top of the hierarchal chain of a typical public school system. Second, in order for change that impacts an entire school system to occur, there must be a mechanism for deep learning prior to and during the implementation stage for members of the district.
\end{abstract}

Keywords: culturally relevant pedagogy, second-order change, decolonizing, sensemaking, university-school partnerships

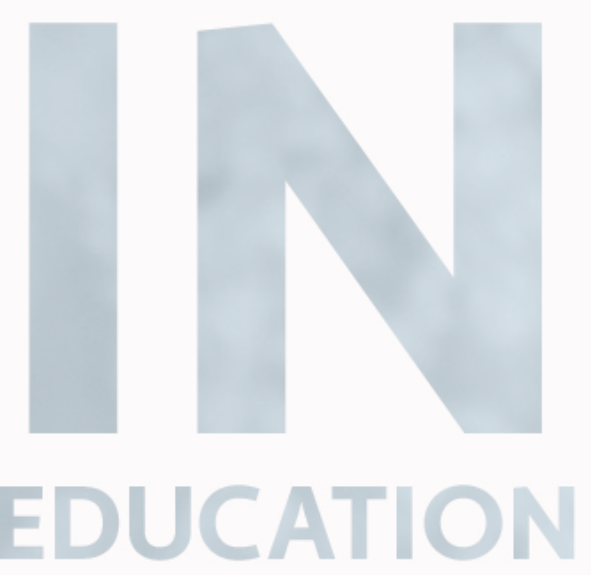




\section{Culturally Relevant Pedagogy —A Diffusion Model for District-Wide Change to Address Systemic Racism}

In educational circles across North America, the conversations about race and education have revolved around the atrocious differences in achievement levels between African American and African Canadian students and their White peers. In Canada, this conversation is particularly relevant in the province of Nova Scotia. Nova Scotia has the largest proportion of Canadian born Black people (Statistics Canada, 2010). According to the Statistics Canada (2013) and the data analysis from the Government of Nova Scotia, Department of African Nova Scotian Affairs (2014), in 2001, Black people in Nova Scotia made up the biggest non-White portion of the population with 80.7 percent of Black people being born in the province. Unlike other provinces in Canada, Nova Scotia has the largest percentage of Indigenous Black people in the country. The history of Black people in Nova Scotia can be traced back to the Atlantic slave trade, which was only abolished in Canada in 1834 (The Canadian Museum for Human Rights, 2021), the arrival of the Black Loyalists in 1783 (Thomas \& Lindsay, 2001) and the arrival of the Jamaican Maroons in 1796 (Black Cultural Centre for Nova Scotia: African Nova Scotian Museum, 2021).

Black people in Nova Scotia also referred to as African Nova Scotians, have not been spared the effects of racism, although historically, Canada has mistakenly been referred to as a haven of freedom and the Great Mosaic. This is particularly true of education. Achievement data show that Black students are behind their peers in both math and literacy at all levels. This gap widens as they continue throughout the system. In 2016, the percentage of Black students in Nova Scotia who demonstrated achievement on provincial assessments in all school boards in Grades 3 , 4,6 , and 8 was far below that of other students disaggregated by ancestry. In Math, less than 50\% of Black students met outcomes in Grades 8 and 10 (Province of Nova Scotia, 2016). Provincial assessment data have communicated to educational leaders that there is a problem; however, it does not point to the root of the problem or a solution (Gay, 2000).

The purpose of this paper, which draws upon a larger instrumental case study that investigated culturally relevant pedagogy (CRP) as a district-wide change, is to demonstrate an effective model for sustainable, deep-level educational change to address systemic racism through CRP. The primary research question from the larger study was: How do people with different roles throughout the hierarchy of the school district make sense of CRP? In this paper, I highlight two of the key findings to demonstrate what is required for CRP to be implemented effectively. First, in order for CRP as a district-wide reform mandate to be implemented effectively, the steps of the reform must be diffused throughout the district rather than decreed from the top of the hierarchal chain of a typical public school system. Second, in order for change that impacts an entire school system to occur, there must be a mechanism for deep learning for the lead team prior to the implementation of CRP and for the system during the implementation phase.

In this paper, I outline the need for a new model of district-wide change through the story of how a school district in Nova Scotia, Canada, made sense of implementing CRP throughout its system. I use the stories of how educators, positioned at all levels of the school district's hierarchical organization, made sense of CRP in pursuit of improving academic success for its Black and Indigenous students. Understanding what is required to implement CRP will uncover changes that are required with the structure of a school district. The implementation of CRP through a deep learning mechanism, along with the change to the way reform is implemented throughout a school district, reveal a diffusion model to avoid barriers that naturally occur while implementing change through an organization where information flows downwards implement 
deep, sustainable changes to the culture of a school district to interrupt systemic practices plaguing Black children.

\section{Literature Review}

Culturally relevant pedagogy targets issues of equity. As a system-wide mandate, CRP is aimed at addressing the low achievement of non-White students. Implementing CRP to improve academic achievement for students from marginalized populations has been examined from a teacher and school perspective (Gay, 2010; Ladson-Billings, 1995a/1995b/2006) but rarely studied as a system-wide intervention or reform mandate. According to Gay (2000), educators are culturally responsive to their students when they use their cultural ways of knowing and being as the focus of planning and building instruction. Ladson-Billings (1995a) described being culturally relevant as a way of being that is culturally competent and socially and conscientiously critical, providing a method for students to be successful. Both scholars agree that effective education requires the culture of the students to be placed at the core of all that is done in the act of educating students. The failures of education reform aimed at creating equitable systems, especially in the province of Nova Scotia, tell us that implementing CRP requires that Black culture and history has not been valued and incorporated within the practices, procedures, and policies of the education system (Black Learners Advisory Committee, 1994; Lee \& Marshal 2009).

In Nova Scotia, the data on student achievement highlight the inequities in its public schools towards Black students. In 1994, the Black Learners Advisory Committee (BLAC) reported on the systemic barriers facing Black Students in Nova Scotia. Among these barriers were racial stereotyping and the overrepresentation of Black students in special education. Lee and Marshall's (2009) follow up to the BLAC Report stated the barriers identified 15 years earlier still persisted and that the recommendations from the BLAC Report had, for the most part, not been implemented. In 2016, the province of Nova Scotia Department of Education's report, entitled Individual Program Plan (IPP) Review: Themes and Recommendations, noted that students placed on individual program plans found the same barriers as the BLAC report (1994). All these reports recommended that culturally relevant instruction be implemented in Nova Scotia provincial schools.

The implementation of CRP involves system, school, and classroom educators understanding the culture of the students they serve and, in turn, using the information they gain as the avenue to make decisions around leadership and instruction (Gay, 2010). Gay noted that a starting point for implementing this reform is to delve into the concept of culture and, in the process, have educational leaders, change agents, and teachers discover their own culture and its impact on their students.

Many anti-racist scholars (Delpit, 2006; Gay, 2010; Lewthwaite \& McMillan, 2010; Milner, 2006; Tileston \& Darling, 2008) have concluded that it is imperative that educators challenge and reflect on their thinking and beliefs about children who are of a different race and culture than their own. This includes coming to the realization that deficit thinking, which views Black students as incapable of succeeding academically compared to their White counterparts, has led to poor academic results (Hilliard, 2004). Deficit thinking has led to stereotypes and low expectations of students. Low expectations due to deficit thinking are evident in student achievement data across the United States and the province of Nova Scotia (Bohrnstedt et al., 2015; Province of Nova Scotia, 2016). "The very view of diversity as a deficit [sic] needs to be reframed if educational reformers are serious about affording all students an equal opportunity to 
learn" (Nieto, 1998, p. 430-431). Once educators understand that it is not the students that have been failing but a Eurocentric colonialist education system that has failed the students, the work of CRP can begin. Using CRP as a district-wide reform will have to include steps to address this deficit thinking and transform the individual beliefs of the educators within the district. This is necessary to eradicate practices that perpetuate racism throughout education.

The steps needed to address deficit thinking can be categorized as decolonizing actions and are the first steps in the implementation of CRP. (Battiste et al., 2002; Hilliard, 1978). Ignoring these steps means that any effort to equitable change an organization or system will ultimately fail. Hilliard III (1978) argued that for true equity within education to succeed, each educator must understand: (a) the concept of culture, (b) that there are varying cultures and linguistic styles, (c) that each person sees the world through their own perceptual lens and each one's reality differs from others, and (d) by forcing students to adapt to a culture other than their own is an aggressive act. Decolonizing one's beliefs involves "understanding and unpacking the central assumptions of domination, patriarchy, racism, and ethnocentrisms that continue to glue the academy's privileges in place" (Battiste et al., 2002, p. 84). It is this glue that has permitted deficit thinking to permeate the school system. Once individuals have come to the realization of "why" what they have been doing has not worked for students or the intended mandate, then they are ready to act.

Colonialism is the foundation of education systems and upholds dominant value systems while denying the value of others. It is this foundation that has blurred belief systems about children whose ancestors were the colonized (Battiste, 2013). To truly address systemic issues, change agents will have to look at how the education system is structured and how information and learning disseminates to educators throughout the school district.

The organizational structure of school districts in Canada has not changed significantly in the last 40 years (Campbell, 1975). School districts in the province of Nova Scotia have a hierarchical structure headed by a district superintendent or regional executive director who reports directly to the provincial government agency charged with the responsibility of overseeing education. This is a system that is similar to that described by Campbell. As a bureaucratic system, a school district's organizational and procedural methods depend on its "rules and regulations, official standard operating procedures, written memos, chain of command" (Owens \& Valesky, 2007 , p. 279). This bureaucratic organizational structure does more than simply position people for the purposes of authority and determining pay scale. By design, it dictates how people are permitted to interact with each other (Meyer, 1984). The limitations of these interactions through communication, isolation of expertise, and a narrowing of decision-making authority cause many organizations to be unable to fully implement change mandates.

Reform endeavours, like CRP, that target equity issues, require that all departments within an organization align to support what happens directly in the classroom (Bishop et al., 2010; Zavadsky, 2009). This includes re-examining how individuals within the hierarchy communicate with each other, how tasks are assigned regardless of traditional department responsibilities, and how collaboration occurs among all levels (Bishop et al., 2010, Coburn, 2003). A reorganization of this type would have educators at all levels within a system directly tied to supporting classroom instruction and school leadership.

With the plethora of research on reforming school districts, one area that is lacking greatly is research that addresses the implementation of initiatives that address racial and cultural inequities (Garcia-Huidobro et al., 2017). Reform agents have not been successful in creating 
sustainable large-scale reforms in this area. Bremer (1973) surmised that failure of reform efforts are not due to the reform itself, but because reform "is scarcely understood" (p. 7). In order to include actions of change that would address inequities based on White colonial culture, these inequities must be recognized, seen, acknowledged, and named (Hilliard, 1978).

The majority of reform efforts to improve academic success for Black students have involved a revolving door of interventions, yet, with a few exceptions, the issues of educational inequity still persist. These efforts have involved such things as student-focused initiatives, including grade-level reading interventions, tracking and monitoring student achievement, and pull-out practices that remove students from the classroom setting to receive individual and small group remediation. These interventions amount to what Hilliard (2004) surmised as "weak educational services that are based on low-level recipes, or commercial programs and educational reforms" (p. xxi). These low-level interventions are also referred to as "first-order changes" (Watzlawick et al., 1974).

First-order changes are those changes that can occur without interrupting the status quo of an organization and do not require changes to the culture, structure, behaviours, or the belief systems of those tasked with making the changes (Bartunek \& Moch, 1987; Cuban, 1998; Fullan \& Stielgelbour, 1991; Kezar, 2001; Levy 1986; Waks, 2007). First-order changes can be made quickly because they fit "into the program's existing values and structure" (Kezar, 2001, p. 32). These first-order changes centre on an approach to fixing the child, not the system.

Whereas first-order changes do not change the culture of an organization, second order change is "transformational change; the underlying values or mission, culture, functioning processes, and structure of the organization change" (Kezar, 2001, p. 32). This approach alters the way business is conducted throughout a school system and is an example of a paradigmatic shift. Therefore, second order change would affect individuals throughout a school system and involve every level because their value sets and belief systems would be examined, challenged, and potentially changed (Kezar, 2001). For such an approach to work, leaders will have to understand the culture of the organization, including the belief systems of individuals, to help them to make sense of the changes being mandated (Iveroth \& Hallencreutz, 2016).

Sensemaking is the process that people use to create an understanding of their experiences. Determining how people occupying different roles within a school system make sense of CRP as a district-wide reform would help to gain an understanding of what is required at each level of a school district to create deep, sustainable, second-order change. Organizational theorist Karl E. Weick formulated seven properties of sensemaking, which form an analysis structure to understand how individuals come to understand their thinking, actions, experiences, and how they make sense of what they believe to be true. Weick's (1995) seven properties, which I used to analyze the research participants' narratives, are: grounded in identity, retrospective, enactive of sensible environments, social, ongoing, focused on and by extracted cues, and driven by plausibility.

Individuals' identities are grounded in their beliefs and values. It is an individual's beliefs and values that direct the way in which they work. For educators, beliefs drive practice. It is the "why" of what they do. When reform mandates are introduced, individuals wrangle with the question, "What the situation means is defined by who I become while dealing with it or what and how I represent" (Weick, 1995, p. 24). As Kezar (2001), Fanon (1967), and Hilliard III (1978) 
have all described, it is one's identity that educators will wrestle with when the change mandate involves the evolving of one's personal beliefs.

Weick's (1995) second sensemaking property, retrospective, is how individuals comprehend information and events after they have occurred. This is the reflective stage that requires time. For educators, this is an important step that is not usually afforded them if they receive the messages of CRP through the usual district-wide communications such as memos or 1-day workshops. This step allows individuals time to come to a state of clarity about CRP with new information being added to their past understanding.

That sensemaking is enactive of sensible environments, Weick's (1995) third property, gives researchers and reform agents important information regarding organizational culture, resistance to change, and how sensemaking is linked to action. The way in which people have made sense of the new information about CRP will be revealed in the actions that they take. The key to school culture is that the people in the organization characterize its culture. The individuals and groups in an organization create the environment in which they are members. Therefore, change agents need to be concerned at the individual level. The actions individuals take may be perceived as resistance or barriers to reform efforts. Barriers to implementing CRP are not externally constructed; rather, the implementers of the reform create those barriers through their actions. The environment, which is created through the changes of reform, is part of the sensemaking process, which, when attended to, can help push reform forward. On the other hand, if change agents do not pay attention to how educators perceive the environmental changes, the enactment of the sensemaker may also halt or suspend progress.

Organizations are socially created by the actions of their members (Iveroth and Hallencreutz, 2016). The social creation provides "both limits and possibilities for new actions" (p. 56). The social sensemaking property is considered the impetus for action (Iveroth \& Hallencreutz, 2016; Weick, 1995). Individuals will act or react as per their sense of changes in their environment or culture through observing and talking with others experiencing the same change. Understanding the social aspect of sensemaking will help guide the steps of those implementing CRP.

Sensemaking never stops. Weick's (1995) fifth property of sensemaking is that it is ongoing. Sensemaking is also emotional. Individuals make sense of current practice while reflecting on past experiences, simultaneously balancing their beliefs with the actions of others. As an ongoing activity, sensemakers are continually reaffirming, modifying, or maintaining their beliefs (Mills, 2003).

While individuals are reaffirming, modifying, or adapting their beliefs through sensemaking, they are taking cues from their environment, past experiences, and others around them. The focus on the extracting of cues is Weick's (1995) sixth property. Cues are reference points to draw meaning from (Iveroth \& Hallencreutz, 2016; Weick, 1995). This stage of sensemaking draws on people's prior knowledge and experience.

The last property of sensemaking is driven by plausibility rather than accuracy (Weick, 1995). The sensemaking process begins with what people think the situation is about and not necessarily with the actuality of the situation. The environment, the social interactions, and past experiences all lend themselves to what could be a facade of the actual changes taking place. 
For reform agents, communication is key here. The changes that actually take place through reform efforts are what makes sense or what is plausible (Weick, 1995). Often in a school district, mandates are passed down from the Ministry of Education to district superintendents. The information is then funnelled through directors to their respective departments. It is then communicated to principals and, lastly, to teachers. This communication pipeline can often be likened to the gossip game. In this game, one person whispers into the next person's ear; this process continues until the last person in the group repeats out loud what they have heard. What the last person utters is usually nowhere near what the original message was. Once the message is out there, it is hard to contradict, whether true or not. Reform agents want to ensure actions that are taken by change implementers are based on accurate information.

It is imperative that educators at all levels receive the same communication and are afforded the same level of learning about CRP. Studies on school reform, particularly those on CRP, outline the failures that can be attributed to the lack of understanding of the system leadership to support educators. Even if a teacher working at the school level has the capacity, they will not likely be able to sustain their work without support from immediate supervisors and system leadership (Parhar \& Sensoy, 2011; Young, 2010). The leaders of an organization shape its culture and, therefore, the reform must start with them (Schein, 2012). In my experience, it is assumed that the leaders of school districts already possess the knowledge and beliefs that are needed to implement new reforms. In the areas of equity, decolonization, and cultural consciousness that are required for CRP, as history has demonstrated, a lack of knowledge and unexamined beliefs of leaders have contributed to the issues of systemic racism and the achievement gap (McCray \& Beachum, 2014).

Prior to the implementation stage of CRP, leader's must reach the point of critical consciousness where they have the ability to (a) recognize and reconcile their past practices, and belief systems about equity and systemic racism; (b) identify deficit thinking and inequitable practices in others; and (c) critically reflect on practices enacted by themselves and others. McCray and Beachum (2014) recognized these steps as liberatory consciousness, pluralistic insight, and reflective practice. This state of being as a system leader will allow the implementation of CRP to be effective.

\section{Theoretical Framework}

The theoretical framework for the original study was informed by both sensemaking and decolonization. Decolonization, in educational circles, is the process by which educators analyze and rethink their beliefs about children based on race and culture (Battiste, 2013). Sensemaking describes the actions individuals take to socially create their realities (Mills, 2003; Weick, 1995). Sensemaking provided the analysis structure for data collection, and decolonization provided the lens through which the data were analyzed. The decolonizing lens allowed me to delve deeper within the seven characteristics of sensemaking: grounded in identity, retrospective, enactive of sensible environments, social, ongoing, extracted by and from cues, and driven by plausibility rather than accuracy (Weick, 1995) to view the actions of educators from an equity perspective (Tuhiwai Smith, 2012).

\section{Methodology}

The research methodology used was an instrumental qualitative case study. The school district in the study was the bounded unit and was chosen because the district's leadership had committed to CRP. The study was concerned not with the school district itself; but, with the phenomena of the 
implementation of CRP by educators who occupied different roles and have had different experiences with their implementation efforts.

The bounded school district encompassed both urban and rural hubs and represented Nova Scotia schools as having a diverse population that included Black and Indigenous students. The leader of the chosen school district had decided to implement CRP to address the racial achievement gaps. Another benefit the school district offered was that educators in different hierarchal roles throughout the district were enrolled in a university Master of Education cohort dedicated to developing culturally relevant educators and leaders.

The data collection methods consisted of interviews of each participant, observations of leadership meetings, administrative walkthroughs of principals' schools, and a document analysis of all reports, memos, and trustee meetings throughout the data collection period. Interviews and observations determined how educators made sense of the implementation of CRP using Weick's (1995) seven characteristics of sensemaking. The document analysis revealed what had been communicated and offered about CRP to all members of the district.

In this study, my goal was to determine how my participants made sense of the implementation of CRP through the stories they created. I documented how these educators' stories transformed as new information challenged the parameters that had held their old stories together (Iveroth \& Hallencreutz, 2016). These data collection methods are consistent with case study methodology (Creswell, 2013; Merriam, 1998; Yin, 2014).

\section{Participants}

Purposeful sampling of participants was used. It was paramount that the participants represented all levels of the hierarchy of the system to be studied. The first two participants represented the top of the hierarchy, the Superintendent and a Senior Director. At the time of this study, three out of the six middle management level and school-based participants (supervisor, principal, and teacher) were selected because of their participation in the Master of Education cohort dedicated to CRP. Additionally, to compare and contrast how educators at these three levels of implementation made sense of CRP, one supervisor, one principal, and one teacher participant who were not on the cohort were chosen using typical sampling (see Table 1 and 2).

\section{Table 1}

Unique Sampling of Participants

\begin{tabular}{|l|l|}
\hline Unique Sampling & Typical Sampling \\
\hline I Supervisor (cohort) & I Supervisor (non-cohort) \\
\hline I Principal (cohort) & I Principal (non-cohort) \\
\hline I Classroom Teacher (cohort) & I Classroom Teacher (non- \\
cohort)
\end{tabular}

\section{Table 1}




\begin{tabular}{|l|l|l|}
\hline Nicole & Non-Cohort Teacher & $\begin{array}{l}\text { White, female, an educator for 2 } \\
\text { years }\end{array}$ \\
\hline Cassandra & Cohort Principal & $\begin{array}{l}\text { Black, female (only Black } \\
\text { participant in the study) an educator } \\
\text { for 21 years. }\end{array}$ \\
\hline Niles & Non-Cohort Principal & $\begin{array}{l}\text { White, male, an educator with the } \\
\text { district for 28 years }\end{array}$ \\
\hline Christina & Cohort Supervisor & $\begin{array}{l}\text { White, female, an educator with the } \\
\text { district for 25 years }\end{array}$ \\
\hline Norman & Non-Cohort Supervisor & $\begin{array}{l}\text { White, male, an educator worked for } \\
\text { the district for 34 years }\end{array}$ \\
\hline Peter & Superintendent & $\begin{array}{l}\text { White, male, an educator for 28 } \\
\text { years, third year as Superintendent }\end{array}$ \\
\hline Patricia & Director/Assistant Superintendent & $\begin{array}{l}\text { White, female, an educator for 31 } \\
\text { years in the same district }\end{array}$ \\
\hline
\end{tabular}

The narratives from the participants gave insight into answering the primary research question: How do people who are positioned in different roles throughout a school district make sense of culturally relevant pedagogical reform? The findings below highlight the narratives of participants at each level of the school district and demonstrate the purpose of this paper: the need for a mechanism for deep learning about CRP throughout the district and the implementation of CRP as a second-order, district-wide change needs to be diffused throughout the system.

\section{Findings}

\section{The Story From the Top}

Weick (1995) noted that the plausibility of a change implementation coming to fruition is dependent upon what each educator knows and understands of how and why to implement the reform. The district's communication about CRP was intertwined with what the leadership thought the district collectively knew and accepted. For participants who were not members of the university cohort, this meant they were only exposed to what was communicated down through the hierarchy of the district. This communication was connected to what was already known from current practices that focused on social justice initiatives. As Hilliard (1978) described, when it comes to issues of race, if it does not affect you personally, it is easily avoided. Each individual in this case study created a new story from which to enact CRP, using what made them feel comfortable and tied to their individual identities prior to the implementation stage.

The new leader of the district, Peter, the Superintendent, felt strongly that, in his role, it was crucial to close the achievement gap affecting Black and Indigenous students in his district. He believed CRP was the means to do so. This stance, which revealed his identity, is what drove his actions when he began his work as superintendent.

To begin his plan to implement CRP, Peter (a superintendent) used the existing practices of the district's culture "which had tweaked [his] interest" as "the jump-off point." For Peter, these practices included the district's social justice framework and relational approach, which were established prior to his arrival. The district's social justice framework consisted of five pillars; race, gender, class, sexual orientation, and abilities (Superintendent Report, September 2017; January 2018). Peter described the district's relational approach as "not about just fixing what's 
broken, it's about doing business in a more relational way, which is about understanding everybody, and being thoughtful and mindful about every decision that we make, who is impacted, and how." By interpreting as he did, Peter was, in fact, merging both frameworks with his definition of CRP, which he described as:

Making sure that everything in the classroom and in the school, in the lived experience of every student, is relevant to them in their lived experience. And making sure that they see themselves reflected in the school and that they connect to what's going on in the school.

Peter took the first possible opportunity to communicate to his school district the direction in which he wanted them to move. He met with all of his district's leaders to announce that his district would be implementing CRP. In his messaging, he linked his identity with the district's frameworks and connected his vision to his district's student achievement data. The data showed clearly, as the majority of school districts in North America, disparities are disaggregated by race. Peter painted a picture of the realities of education for the district's Black and Indigenous students. Peter publicly declared: "Despite the fact that we know there is no achievement gap at birth, some of our African-Nova Scotian and First Nation learners are not achieving at the same level as some of their classmates" (Superintendent Report, December 2015). He also acknowledged, "When we take a close look at assessment data and see that, overall, our African-Nova Scotian and First Nation learners are achieving at lower rates than their classmates, we know there is a systemic issue" (Superintendent Report, December 2015). By raising awareness of the disaggregated results and how current teaching practices are failing to address them, Peter laid the foundation for the decolonizing process for the leaders of his district.

Peter's intention was to move his district in a new direction. However, the message that landed, as evident in the participants' stories, was that educators were to build upon relational theory and their existing social justice framework campaigns to implement CRP. District messaging did not allow for the continuous acknowledgment of the role that systemic racism plays in the underachievement of Black and Indigenous students in Nova Scotian schools. Therefore, the implementation of CRP did not help educators to comprehend concepts of white supremacy and how their biases may serve to disseminate oppressive attitudes and practices.

With the exception of the district members who were participants in the university CRP cohort, in general, educators were not given the opportunity to genuinely explore the colonization of schooling and the effects of systemic racism on non-White students as part of the implementation process. Failing to address race and, by extension, systemic racism from the concept of CRP fundamentally changed how it was understood by participants. The cohort participants, on the other hand, had additional opportunities for sensemaking about race and antiracism, which resulted in different understandings of the CRP reform.

\section{Enacting Change at the Senior Management Level}

Observations of discussions at the senior management level revealed the implementation of CRP was clashing with the existing story of the district, which detailed the equity efforts around its social justice framework and relational approaches. To implement and support change, there needs to be a common understanding of the change itself (Parhar \& Sensoy, 2011; Schein, 2012). At the senior staff level, observation data revealed two truths. First, all members were committed to providing equitable supports to schools. Second, members had not developed a consensus of what CRP actually was or what it entailed. This was evident as senior staff members discussed providing equitable supports to schools. Through the conversations about implementing CRP, 
there were constant reminders from and to members of, we "also support schools with social justice” (Senior Management Meeting, Field Notes, February 22, 2018).

It was also revealed at the senior table that the efforts of the district to implement CRP in schools were operating as a voluntary measure, and there were schools that were not opting in "because they do not have the awareness and mindset [of CRP, and] that brings fear" (Senior Management Meeting, Field Notes, February 22, 2018). This created an uncomfortable environment where existing stories about the purpose and practices to enact CRP were being challenged by this new story.

In order for members of senior management to accept that a different model was needed, they needed time and education to understand and embrace what CRP is and how to utilize it as a strategy to address the systemic barriers that were hindering the academic achievement of nonWhite students.

\section{Two Supervisors Focused on CRP: Different Results}

The two supervisors of schools from the study were Norman, the supervisor who did not participate in the university cohort, and Christina, who did. Throughout the implementation of CRP in their district, they acted on what they felt was a moral imperative that was tied to their identities, which focused on an equitable and socially just education system. Both supervisors acknowledged the academic issues documented for Black and Indigenous students in their district. The difference between the two narratives is that Christina possessed more in-depth knowledge of CRP, the history of schooling for both Indigenous and Black people, and had the opportunity to put her learning into practice simultaneously.

For Norman (a non-cohort supervisor), his actions involved sharing the knowledge he already possessed from past learnings that made up his identity. This included emphasizing the need for educators to become "aware of [students'] culture...historically...knowing who they are today, knowing where they've come from, and the journey they've been on.". Norman believed that a key priority was that students' culture needed to be recognized first. He went on to explain that you could then use "that information when you make decisions for our schools." (Norman's understanding of the importance of students' culture as the basis for decision making reminds me of what Gay (2010) posited: "Culture is at the heart of all we do in the name of education" (p. 8).

Norman understood why CRP was important. However, he was just beginning to go through the decolonizing process himself. Therefore, he could only share his own story of CRP to the extent that it was developed and how it was strengthened by the messages from the Superintendent and through some materials shared with him by his colleagues who were in the CRP cohort.

Christina's (cohort supervisor) actions involved a deeper awareness of CRP and of how to implement it. Her learning within the university cohort provided her with more time to self-reflect about her own feelings regarding race and culture, and she also had the experience of being in continuous communication with her university cohort peers who were also making sense of CRP. Christina shared,

The work that I've been doing as part of the cohort has been the best educational experience that I have had...it's given me the language, I think, and the ability to articulate around why this work is important. And the ability to support principals, and really look at practices and question them...We have to question ourselves, question our motives, 
question why we want practices to continue, who that works for, who that doesn't work for.

Through her experiences in the graduate cohort, Christina was also guiding her principals and other educators she worked with through the CRP journey.

\section{Same District, Differing Journeys to CRP Leadership}

Both of the school principals in the study started their journey with a willingness to implement CRP. Niles, the non-cohort principal, took actions based on the messages that flowed down from the district level. These messages were filtered through his supervisor, Norman (whose sensemaking journey is discussed above) For Niles (non-cohort principal), this resulted in a lack of deep understanding of CRP and a lack of knowledgeable support from those higher than him on the organization chart. Niles believed it was part of his role as principal to assist teachers in looking "through different lenses, instead of just maybe a White, Eurocentric lens." However, he also felt that CRP "a lot of times, it will depend on the classroom. The teacher is...the one that's in charge of that classroom." He was willing and had great intentions; however, he lacked the indepth knowledge and experience required to lead the implementation of CRP.

Cassandra, the university cohort principal, through her learning and simultaneous actions to implement CRP in her school, was able to deepen not only her own understanding of the change mandate but also the understanding of her teachers. Her university learning gave her the opportunity to grow in her knowledge and confidence as an instructional leader. Cassandra shared,

Being a leader is very complex...culturally relevant pedagogy, and the implementation of it at our [district] level, has completely changed me as a leader because it has forced me to reflect critically on everything. On my practice, on my communication with teachers, on professional practices, and where that fits...culturally relevant pedagogy, it drives the bus on everything... as a leader, after going through a year of conversations with teachers, about data, about everything that has to do with learning about kids, their stories, our community, it has just changed the way I align how I do business...I have grown).

Furthermore, she was learning CRP alongside her own supervisor and others who were in the cohort and who were in leadership positions within the district. This enabled Cassandra to look at the process of implementing CRP from a system's perspective. She viewed herself as a change agent within the system, which was both a benefit and a barrier for Cassandra. She had the knowledge and the willingness to implement CRP at her school site; however, those she relied on to support her teachers did not. The math and literacy consultants assigned to her school had received the same messaging from the district as all other non-cohort educators, so oftentimes, Casandra felt alone in her efforts. The convergence of experiences for Cassandra enabled her to advance CRP further in her own school than Niles was able to do, and she was actually well ahead of where the system, as a whole, found itself.

\section{Culturally Relevant Teachers, Implementing What They Know}

As with the other participants in this study, both Cory, a cohort teacher, and Nicole, a noncohort teacher, were eager to put into action the learning they received about CRP. They were willing to do whatever they could with the knowledge they had to improve schooling for the children they served. However, they brought very different experiences that shaped the same change initiative and were provided with very different support for their sensemaking journey. 
Nicole was an enthusiastic beginning teacher who had limited personal or academic experiences to equip her to understand racial and cultural differences. Cory was a mid-career teacher who had lived, worked, and studied in diverse contexts that supported his understanding of cultural differences from a more socially critical stance. Cory was provided with multiple opportunities to continuously reflect upon and practice being a culturally relevant educator. Nicole was given only a few very surface level opportunities to do this.

It is not surprising, then, that Nicole's understanding of the definition of culture is reminiscent of the original messages found in the district's Superintendent's Report (Superintendent Report, Oct. 2015) about CRP as linked to what the district was doing in terms of social justice and relational theory. When asked to describe CRP, Nicole (non-cohort teacher) stated: "But a lot of it [CRP] is, you know, making those connections with kids, based on their own culture, and understanding the why and how behind their behaviours and..., kind of, nature in our classroom". Her sensemaking journey of CRP closely matched her prior experiences and the surface level notions of CRP projected by her district. When asked what she would tell others about CRP, Nicole replied, "I usually start by talking about the fact that it is not about race...that we're talking about the different cultures in our area." Nicole's sensemaking journey followed along the same path as the other non-cohort participants in this study. The district's leadership messages impacted all non-cohort participants in a similar way. Without the benefit of professional learning about CRP and time to decolonize their thinking, actions from educators at each level of the organization chart remain relatively the same.

\section{Discussion}

As I began this study, my goal was to seek to understand how educators, with different roles within a school district, made sense of and implemented CRP. One of the findings was where individuals are positioned in the hierarchy of the school district greatly affects the depth of information they receive regarding the change initiatives. The hierarchy controls what information is granted to educators according to their positionality within the system. No matter what the intentions of the original messaging were, starting from the bottom of the organization chart, messages rely on how individuals on one level above made sense of the communication about CRP. The result of being constrained by the organizational hierarchy did not allow for the learning and decolonizing to happen for members throughout the district.

The three cohort participants, while implementing what they were learning within their specialized graduate program, were able to make changes to their practices to become culturally relevant. The cohort supervisor, Christina, while only able to work with the principals within her family of schools, was able to deeply influence these individuals in ways that she could not have otherwise. Cassandra, the cohort principal, was limited by the constraints from the lack of understanding about CRP from her district instructional supports but, nonetheless, was able to influence her own teachers quite significantly because of what she was learning in her cohort. Cory had the greatest ability to impact students and was successful in working with his principal to implement CRP directly in his classroom. On the other hand, the progress of the non-cohort members was stifled by a lack of learning and communication. The findings of this paper make it strikingly apparent for the need for deep-level learning to occur to effectively implement districtwide second order change through $\mathrm{CRP}$ and a method to communicate learning through the entire district.

\section{A Mechanism for Deep Learning: University and School District Partnerships}


School districts, due to the constraints of funding and time, are not able to create the conditions for deep learning required to implement CRP effectively. The learning required begins with the decolonizing steps. This includes, as explained by McCray and Beachum (2014) and Tuhiwai Smith (2012), having educations at all levels of the system reach the stages of critical consciousness, reflection, and pluralistic insight. This can only be accomplished by setting up a learning regimen that allows all educators to truly understand their own culture and its impacts on students who are of another culture. Educators have to recognize, value, and accept the cultural, learning, and communication styles of their students. Educators also have to understand how to incorporate this knowledge into their lessons (Gay, 2000; Hilliard, 1978). Educational leaders must internalize this learning and be prepared to articulate systemic issues when they are occurring and provide solutions.

To counter the issue of time and funding to provide such learning, school districts can easily partner with university faculties of education. School district-university partnerships make logical unions since both are responsible for improving educational leadership and teaching to improve student achievement. At the university level, classes are designed to provide both inservice teachers and preservice teachers the opportunities to increase their knowledge and skills in all areas of education by providing time, guidance, and opportunities to process their learning (Seller \& Hannay, 2010, p. 197). Universities are not bounded by the same time restrictions and funding requirements as school districts. For instance, university faculties can work together in partnership with school districts to develop learning plans for individual schools, groups of schools, and leadership teams. Through such a partnership, school districts would have access not only to research but also to the researchers themselves (Glickman et al., 2014). The benefits of university partnerships would also extend to the universities. Researchers would have access to the field in which they are studying (Seller \& Hannay, 2010). Once the learning has occurred, for at least the leaders of the district, the implementation of CRP can begin.

\section{A New Model for Change}

The findings for this study suggest that implementing CRP as a second order district-wide reform requires a model that allows for diffusion of CRP throughout the district. The stories of the research participants demonstrate how working to implement change within the stringency of a hierarchical system can be stifling and can create barriers between levels.

In order for CRP to be implemented effectively, a school district needs to move away from its business model, where information flows downward, to a model where knowledge and information can be diffused throughout the district. There needs to be a reimaging of the positionalities that would make up the membership of the team leading the implementation of the change. In a traditional school district's hierarchy, communication flows from the senior leadership team down to the teacher level, passing through the filters represented by the understanding of the directors, supervisors, and principals, to finally reach the level of impact at the student level. Using the top-down traditional method of communication and change is like trying to implement CRP by pouring information down a funnel-except the funnel has holes in it. What comes out of the end of the funnel is only what managed to survive past the holes. The surviving filtered product, streaming out of the funnel, is what is left to impact students. The surviving bits do not represent the totality of what needs to happen throughout all of the levels of the district to truly impact student achievement. 
When thinking of change that permeates all aspects of the district, the knowledge, skills, and attitudes need to be diffused throughout the system to touch all individuals within the district, no matter their positionality. For this to happen, the leadership team should be comprised of members who have different organizational roles throughout the system and have acquired the necessary knowledge and reached a point of critical consciousness. For example, the leadership team would include the superintendent, directors, supervisor(s), content area specialists, principals, and teachers (See Figure 1). There also needs to be representation from the groups to which the change mandate is aimed. For the diffusion of CRP, that would require lead team members from the communities the implementation of CRP is meant to address: Black and Indigenous. In order for the diffusion of change to be successful, the leadership team needs to consist of educators that have already obtained the requisite knowledge. The leadership team would be the early adopters and be in a position to begin communication of the diffusion (Rogers, 1983).

\section{Figure 1}

\section{Diffusion of Change Model for School Districts}

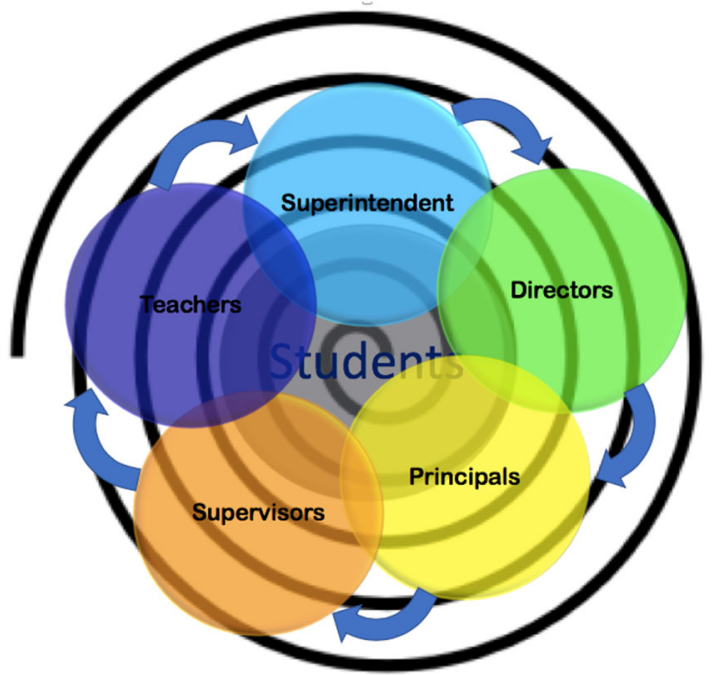

Thinking of change as diffusion would allow the knowledge, skills, and attitudes within the leadership team to spread throughout the district and affect the enormous number of people required for the culture of the organization to change. Using the process of diffusion to implement $\mathrm{CRP}$, the reimagined decolonizing lead team would be working, at the same time, through all the levels of the school board and collaborating with each other to implement CRP (Rogers, 1983). In a sense, the boundaries created by the hierarchical structure of the district (Weber, 1947) determines who gets to work with whom and how would become more porous and flattened. The sharing of information would be cyclical instead of top-down. In this way, the learning and sharing would be continuous and not be blocked at any level. (See Figure 1)

With a leadership team that has been immersed in the deep learning required to implement CRP, the starting story of the implementation would likely begin with asset-, rather than deficit-, thinking. Battiste (2013) noted that decolonizing education involves the unpacking of who controls the knowledge. A lead team that has already taken time to work on changing their individual stories through decolonizing and sensemaking processes could serve to affirm and honour students that are currently being harmed by colonizing practices in education. Hale (2001) and Kuykendall 
(2004) both stated that Black children do not start school disadvantaged; however, it is through schooling based on colonialist and white supremacist attitudes and practices that they find themselves at a disadvantage. A lead team that represents the organizational and racial diversity of the system is much more likely to be able to delve more deeply into systemic issues such as racism and white supremacy, the eradication of which is necessary for the implementation of CRP. The leadership team would be focused on changing the culture of the organization through decolonization. This would, in turn, begin to interrupt the inequitable practices that have led to the achievement gap. CRP, implemented across a whole district, would start to live up to its promise to create an equitable school system (Gay, 2010; Ladson Billings 1995a/1995b).

\section{Conclusion}

This study is significant for several reasons. First, because the findings give educational leaders insight into what is necessary to create deep-level sustainable district-wide reform from the perspectives of educators within all levels of a school. This research also enhances the current thinking on educational reform and CRP by exploring it through sensemaking and decolonizing frameworks. Sensemaking and decolonizing, individually, are well-established theoretical frameworks (Battiste, 2013; Tuhiwai Smith, 2012; Weick, 1995) but have rarely been used together.

I recognize the results of this study are based on one school district in the province of Nova Scotia, Canada. However, this school district, as a bounded unit, had a similar population to most school districts in the province of Nova Scotia, being largely staffed with White teachers with a population of Black students. This makes this study transferable throughout Nova Scotia and beyond because the findings and conclusion have led to a model for effectively implementing CRP as a second-order reform across a school district. 


\section{References}

Bartunek, J. M., \& Moch, M. K. (1987). First-order, second-order, and third-order change and organization development interventions: A cognitive approach. The Journal of Applied Behavioral Science, 23(4), 483-500. https://doi.org/10.1177/002188638702300404

Battiste, M. (2013). Decolonizing education: Nourishing the learning spirit. Purich.

Battiste, M., Bell, L., \& Findlay, L. M. (2002). Decolonizing education in Canadian universities: An interdisciplinary, international, Indigenous research project. Canadian Journal of Native Education, 26(2), 82-95. https://eric.ed.gov/?id=EJ665132

Bishop, R., O'Sullivan, D., \& Berryman, M. (2010). Scaling up education reform: Addressing the politics of disparity. NZCER Press.

Black Cultural Centre for Nova Scotia: African Nova Scotian Museum. (2021). The Maroons. https://www.bccnsweb.com/web/our-history/the-maroons/

Black Learners Advisory Committee. (1994). BLAC report on education: Redressing inequity-empowering Black learners.

Bohrnstedt, G., Kitimitto, S., Ogut, B., Sherman, D., \& Chan, D. (2015). School composition and the Black-White achievement gap (NCES 2015-018). U.S. Department of Education, Washington, DC: National Center for Education Statistics. http://nces.ed.gov/pubsearch

Bremer, J. (1973). Preface. In D. Myers (Ed.), The failure of educational reform in Canada (pp.7-10). McClelland and Stewart.

Campbell, R. F. (1975). The organization and control of American schools ( $3^{\text {rd }}$ ed.). Merrill Publishing.

The Canadian Museum for Human Rights (CMHR). (2021). The story of slavery in Canadian history. https://humanrights.ca/story/the-story-of-slavery-in-canadian-history

Coburn, C. E. (2003). Rethinking scale: Moving beyond numbers to deep and lasting change. Educational Researcher, 32(6), 3-12. https://doi.org/10.3102/0013189x032006003

Creswell, J. W., \& Creswell, J. W. (2013). Qualitative inquiry \& research design: Choosing among five approaches (3rd ed.). SAGE.

Cuban, L. (1998). A fundamental puzzle of school reform. The Phi Delta Kappan, 69(5), 340344. https://doi.org/132.174.255.250

Delpit, L. D. (2006). Other people's children: Cultural conflict in the classroom (2 ${ }^{\text {nd }}$ ed.). New Press.

Fanon, F. (1967). Black skin, white masks. Pluto Press.

Fullan, M., \& Stiegelbauer, S. M. (1991). The new meaning of educational change ( $2^{\text {nd }}$ ed.). Teachers College Press.

Garcia-Huidobro, J. C., Nanneman, A., Bacon, C. K., \& Thompson, K. (2017). Evolution in educational change: A literature review of the historical core of the Journal of Educational Change. Journal of Educational Change, 18(13), 263-293. https://doi.org/10.1007/s10833-017-9298-8

Gay, G. (2000). Culturally responsive teaching: Theory, research, and practice. Teachers 


\section{College Press.}

Gay, G. (2010). Culturally responsive teaching: Theory, research, and practice ( $\left.2^{\text {nd }} \mathrm{ed}.\right)$. Teachers College Press.

Government of Nova Scotia, Department of African Nova Scotian Affairs. (2014). African Nova Scotians Today. https://ansa.novascotia.ca/sites/default/files/inline/documents/ansa-statsresearch-2014-11.pdf

Glickman, C. D., Gordon, S. P., \& Ross-Gordon, J. M. (2014). Supervision and instructional leadership: A developmental approach (9th ed.). Pearson.

Hale, J. E. (2001). Learning while Black: Creating educational excellence for African American children. Johns Hopkins University Press.

Hilliard, A. (2004). Forward. In C. Kuykendall (Ed.), From rage to hope: Strategies for reclaiming Black \& Hispanic students (pp. xix-xxv). Solution Tree.

Hilliard, A. G. (1978). Equal educational opportunity and quality education. Anthropology and Education Quarterly, 9(2), 110-126. https://doi.org/132.174.255.250

Iveroth, E., \& Hallencreutz, J. (2016). Effective organizational change: Leading through sensemaking. Routledge.

Kezar, A. J. (2001). Understanding and facilitating organizational change in the 21st century: recent research and conceptualizations. Jossey-Bass.

Kuykendall, C. (2004). From rage to hope: Strategies for reclaiming Black \& Hispanic students. Solution Tree.

Ladson-Billings, G. (1995a). Toward a theory of culturally relevant pedagogy. American Educational Research Journal, 32(3), 465. https://doi.org/10.2307/1163320

Ladson-Billings, G. (1995b). But that's just good teaching!: The case for culturally relevant pedagogy. Theory Into Practice, 34(3), 159-165. https://doi.org/10.1080/00405849509543675

Ladson-Billings, G. (2006). "Yes, but how do we do it?" Practicing culturally relevant pedagogy. In J. Landsman \& C. W. Lewis (Eds.), White teachers / Diverse classrooms: Creating inclusive schools, building on students' diversity, and providing true educational equity (pp. 29-42). Stylus.

Lee, E., \& Marshall, C. (2009). Reality check: A review of key program areas in the BLAC report for their effectiveness in enhancing the educational opportunities and achievement of African Nova Scotian learners. Nova Scotia Department of Education. https://acs.ednet.ns.ca/sites/default/files/REALITY CHECK FINAL_REPORT FOR W $\underline{\text { EB.pdf }}$

Levy, A. (1986). Second-order planned change: Definition and conceptualization. Organizational Dynamics, 15(1), 1-5.

Lewthwaite, B., \& McMillan, B. (2010). "She can bother me, and that's because she cares": What Inuit students say about teaching and their learning. Canadian Journal of Education, $33(1), 140-175$.

McCray, C. R., \& Beachum, F. D. (2014). Countering plutocracies: increasing autonomy and 
accountability through culturally relevant leadership. School Leadership \& Management, 34(4), 392-413. https://doi.org/10.1080/13632434.2014.943171

Merriam, S. B. (1998). Qualitative research and case study applications in education. JosseyBass.

Meyer, J. W. (1984). Organizations as ideological systems. In J. E. Corbally \& T. J. Sergiovanni (Eds.), Leadership and organizational culture: New perspectives on administrative theory and practice (pp. 186-206). University of Illinois Press.

Mills, J. H. (2003). Making sense of organizational change. Routledge.

Milner, H. R. (2006). But good intentions are not enough: Theoretical and philosophical relevance in teaching students of colour. In J. Landsman \& C. W. Lewis (Eds.), White teachers/diverse teachers: A guide to building inclusive schools, promoting high expectations, and eliminating racism (pp. 79-90). Stylus.

Nieto, S. (1998). Cultural difference and educational change in a sociopolitical context. In A. Hargreaves, A. Lieberman, M. Fullan, \& D. Hopkins (Eds.), International handbook of educational change: Part one (pp. 418-439). Kluwer.

Nova Scotia Department of Education. (2016). Individual program plan (IPP) review: Themes and recommendations. https://www.ednet.ns.ca/docs/individualprogramplanreview.pdf

Owens, R. G., \& Valesky, T. C. (2007). Organizational behavior in education: Adaptive leadership and school reform (9th ed.). Allyn \& Bacon.

Parhar, N., \& Sensoy, O. (2011). Culturally relevant pedagogy redux: Canadian Teachers' conceptions of her work and its challenges. Canadian Journal of Education, 34(2), 189 218. https://journals.sfu.ca/cje/index.php/cje-rce/article/view/347

Province of Nova Scotia. (2016). Disaggregated results: Nova Scotia Assessments. https://plans.ednet.ns.ca/disaggregated-results

Rogers, E. M. (1983). Diffusion of innovations ( $3^{\text {rd }}$ ed.). The Free Press.

Rozen, G. (2001). Education for self-determination. American Review of Canadian Studies, 31(1-2), 61-70. https://doi.org/10.1080/02722010109481582

Schein, E. (2012). Organizational culture and leadership (4 ${ }^{\text {th }}$ ed.). Jossey-Bass.

Sellar, W., \& Hannay. (2010). Inside-outside change facilitation: Structural and cultural considerations. In N. Bascia \& A. Hargreaves (Eds.), The sharp edge of educational change: Teaching, leading and the realities of reform (pp. 217-236). Routledge.

Statistics Canada. (2010). Canada's ethnocultural mosaic, 2006 census: Canada's major census metropolitan areas. http://www12.statcan.gc.ca/census-recensement/2006/as-sa/97562/p18-eng.cfm

Statistics Canada. (2013, May 6). National household survey (NHS) profile, 2011. https://www12.statcan.gc.ca/nhs-enm/2011/dp$\mathrm{pd} /$ prof/details/page.cfm?Lang $=\mathrm{E} \& \mathrm{Geo} 1=\mathrm{PR} \& \mathrm{Code} 1=12 \&$ Data $=$ Count $\&$ SearchText $=\mathrm{No}$ va $\% 20$ Scotia $\&$ SearchType $=$ Begins $\&$ SearchPR $=12 \& A 1=$ Visible $\% 20$ minority $\& B 1=A 11 \&$ Custom $=\& \mathrm{TABID}=1$

Tileston, D. W., \& Darling, S. K. (2008). Why culture counts: Teaching children of poverty. 
Solution Tree.

Thomas, N., \& Lindsay, M. (2001). Remembering Black loyalists-Who were Black loyalists? Government of Nova Scotia. https://novascotia.ca/museum/blackloyalists/who.htm

Tuhiwai Smith, L. (2012). Decolonizing methodologies: Research and Indigenous peoples ( $2^{\text {nd }}$ ed.). Zed Books.

Waks, L. J. (2007). THE concept of educational change. Educational Theory, 57(3).

Watzlawick, P., Weakland, J. H., \& Fisch, R. (1974). Principles of problem formation and problem resolution. W. W. Norton.

Weber, M. (1947). The theory of social and economic organization (A. R. Henderson \& T. Parsons, Trans.). William Hodge.

Weick, K. E. (1995). Sensemaking in organizations. SAGE.

Yin, R. K. (2014). Case study research: Design and methods (5th ed.). SAGE.

Young, E. (2010). Challenges to conceptualizing and actualizing culturally relevant pedagogy: How viable is the theory in classroom practice? Journal of Teacher Education, 61(3), 248260. https://doi.org/10.1177/0022487109359775

Zavadsky, H. (2009). Bringing school reform to scale: Five award-winning urban districts. Harvard Education Press. 